\title{
Behaviour of Prestressed Monoblock Concrete Sleepers (PMCS) Subjected to Static Loading
}

\author{
Kay Dora Abdul Ghani, Che Mohd Hilmi Safiuddin Che Jamaludin Mahmud, Mohd Ikmal \\ Fazlan Rozli, Norliyati Mohd Amin
}

\begin{abstract}
In Malaysia, there have been many mode of transportation created to ease the movability of its people from one place to another in short period of time. One of them is rail transportation as it provides many services along the countries. Not only it can transport passengers, train services also transport goods everyday in large quantitties and allocate in short period of time. Many people fond of this transportation due to its low service charge but provides comfortable and safety riding experience whether in short or long destination. Due to high demand of train transportation, it is important to have their structural integrity remain in high quality to avoid any damage and accident occur in the future. One of the most important component in railway structures is Prestressed Concrete Sleeper (PCS). Therefore, it is important to investigate its load capacity and capabilities to avoid any high risk to occur not only to train and its cargo, but to the safety of the passengers as well. Prestressed Monoblock Concrete Sleeper (PMCS) mainly involved in this research paper due to its majority usage in Malaysia by KTMB and positive and negative moment test were chosen to investigate the design and ultimate load under static loading referring to Australian Standard (AS 1085.14-2012).
\end{abstract}

Keywords: Australian Standard, Negative Moment Test, Positive Moment Test, Prestressed Monoblock Concrete Sleeper

\section{INTRODUCTION}

Rail transportation has become one of the busiest transportation services in Malaysia due to its availability, servicebility and flexibility to move from one place to another. The number of passengers surely are increasing every year, resulting to frequent maintenance to keep the quality in the optimum level. To ensure the rail transportation such as train services to provide good services, railway structure mainly concrete sleeper need to be focus on because it plays an important part to hold the gauge intact and distributing loads to the ballast bed underneath it.Prestressed monoblock concrete sleepers are structures that support railway system and absorb variable loading from the train that pass along the rail [1].

Revised Manuscript Received on November 05, 2019.

* Correspondence Author

Kay Dora Abdul Ghani, Senior Lecturer, Faculty of Civil Engineering, Universiti Teknologi MARA, Cawangan Pulau Pinang, 13500 Permatang Pauh, Pulau Pinang. Email: kaydoraabdghani@gmail.com

Che Mohd Hilmi Safiuddin Che Jamaludin Mahmud, Research Assistant, Faculty of Civil Engineering, Universiti Teknologi MARA, Cawangan Pulau Pinang, 13500 Permatang Pauh, Pulau Pinang. Email: hilmisafiuddin@gmail.com

Mohd Ikmal Fazlan Rozli, Senior Lecturer, Faculty of Civil Engineering, Universiti Teknologi MARA, Cawangan Pulau Pinang, 13500 Permatang Pauh, Pulau Pinang. Email: ikmalcivil@gmail.com

Norliyati Mohd Amin, Senior Lecturer, Faculty of Civil Engineering, Universiti Teknologi MARA, 40450 Shah Alam, Selangor. Email: norli830@uitm.edu.my
The reliable railroad associations relationship with neighboring states are a key trademark that may portray the structure of the rail framework. Malaysian railroads are facing difficulties to improve their firm quality and speed, retaining the true objective to offer striving organizations and improve their centrality as an elective method of transportation.

This research will show the results of failure of PMCS under the static loading that can be completely relevant to the concrete sleepers available in Malaysia and using past researcher's results as a references [2], [3]. Shear and flexure failure are produced by static load while shear failure only occur due to impact load [4]. According to the latest standard, PCS is produced based on Australia standard (international AS1085.14) [5]. Several factors including relative of mass, rate of velocities, contact zone stiffness, loading frequency, impact precision and locally energy-absorbed area can be influential to prestressed concrete sleeper [6]. From previous research, internal frictions among concrete, cement and aggregate can propagate to crack development, resulting to damping coefficients and increasing crack incurrence [7]. The in-situ conditions of railroad concrete sleeper were reproduced. The targets of this paper are to decide the failure of PMCS under the static loading and to relate the relationships between load, deflection, and strain in the form of a chart. The information acquired will be useful as references to help any researcher with respect to railroad sleepers. Additionally, the prior information and present work are required for references. Therefore, this study may provide further information on PMCS and its design, if there is a need to improve its present administration and quality.

\section{METHODOLOGY}

Prestressed Monoblock Concrete Sleeper or PMCS are one of the essential components in railway structures to hold the rail intact. The pressure subjected from the train will be transferred to rail and rail to PMCS. Nowadays, PMCS are mainly used in Malaysia compared to timber sleeper due to its availability and high cost. Inspecting the PMCS to identify pre-crack was conducted before the test. Negative moment test was conducted before positive moment test to check whether the PMCS can withstand its design load, ensuring its quality and strength to use in railway track. To detect pre-crack easier, the surface of PMCS were wiped with drenched material to make it more visible to detect by using High Precision Microscope. According to Australian Standard, three bending moment test are used to conduct negative moment test. There will be two support and one loading subjected directly at the rail seat, meanwhile the other end is in free hanging condtion.

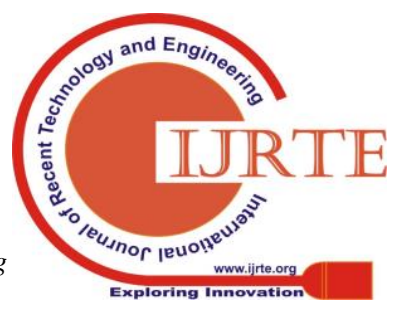


Linear Variable Differential Transformer (LVDT) was applied to measure the deflection happened in negative and positive moment test.

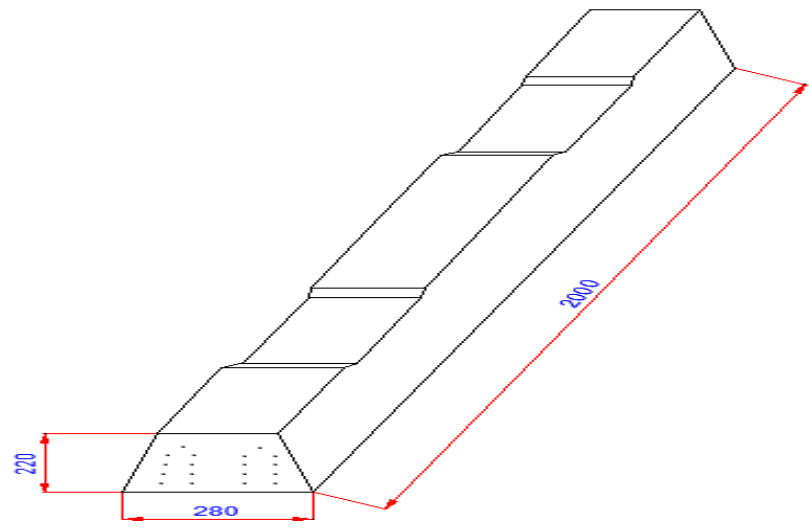

Fig. 1.Sketching of the PMCS.

Figure 1 shows the sketch of PMCS, produced by Autocad to show its dimensions and the number of prestressed tendon in it. PMCS samples that were used contains 18 tendons and its concrete grade is 60 . Three samples were used for positive and negative moment test. 1 LVDT was applied below the PMCS, assigned as L1 to record any displacement of the PMCS. Meanwhile, 2 LVDT was applied at the tendon of the PMCS, assigned as L2 and L3 to record any displacement of the tendon in PMCS. As shown in figure 2, L1, L2 and L3 was assigned at their designated place during negative moment test. Figure 3 depicts the location to support and loading to subject to PMCS with dimensions in millimeters. As we can see, the position of PMCS is in opposite state from original to proceed with negative moment test.

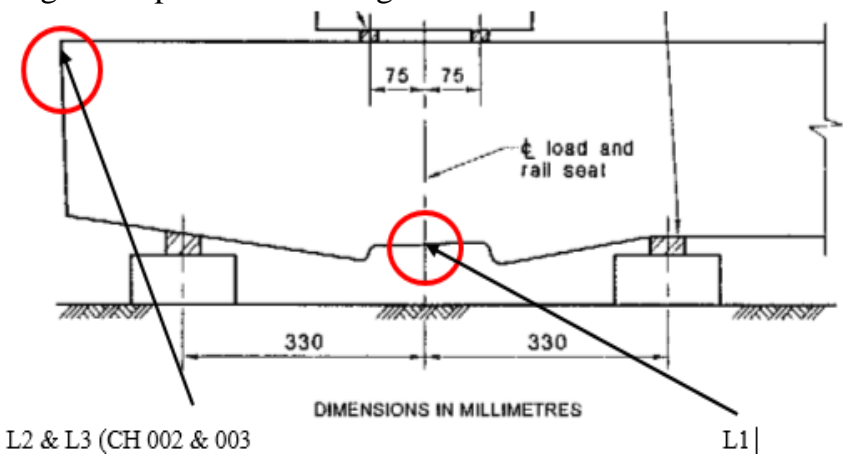

Fig. 2.LVDT placement in negative moment test.

In this experiment, PMCS was setup into the reaction frame according to Australian Standard like in figure 2 and 3. Computer and data logger were prepared earlier and connected together with L1, L2 and L3 to record its reading. By the Standard, the load rate must be $25 \mathrm{kN} / \mathrm{min}$ or 0.42 $\mathrm{kN} / \mathrm{sec}$ to reach PMCS's design load, $176.94 \mathrm{kN}$ to create proof rail seat negative moment. In 3 minutes, the design load was maintained and during that time, any cracks occur was recorded by using any recording instrumental such as camera and video camera. High precision microscope were also used to record any micro displacement created during the test. Finally, the data will be transferred and recorded in the computer for further analysis. Following the similar steps, the other end of the PMCS was tested as well.

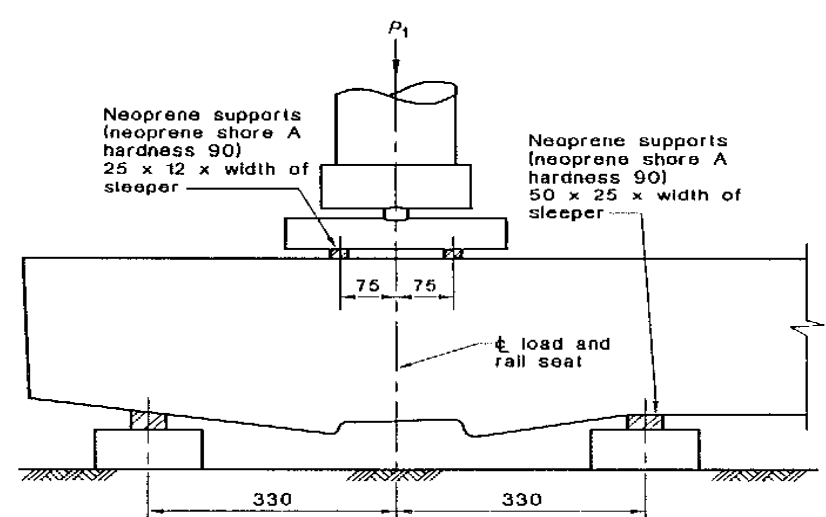

Fig. 3.Support and loading placement in negative moment test.

Furthermore, positive moment test was conducted after negative moment test to check whether the PMCS can withstand its ultimate load, ensuring its quality and strength to use in railway track. According to Australian Standard, three bending moment test are used to conduct positive moment test. There will be two support and one loading subjected directly at the rail seat, meanwhile the other end is in free hanging condtion. Linear Variable Differential Transformer (LVDT) was applied to measure the deflection happened in negative and positive moment test. 1 LVDT was applied below the PMCS, assigned as L1 and 1 LVDT was applied at the upper side position of PMCS, assigned as L4 to record any displacement of the PMCS. Meanwhile, 2 LVDT was applied at the tendon of the PMCS, assigned as L2 and L3 to record any displacement of the tendon in PMCS. Figure 4 depicts the location to support and loading to subject to PMCS with dimensions in millimeters. As we can see, the position of PMCS is in original state to proceed with positive moment test. As shown in figure 5, L1, L2, L3 and L4 was assigned at their designated place during positive moment test.

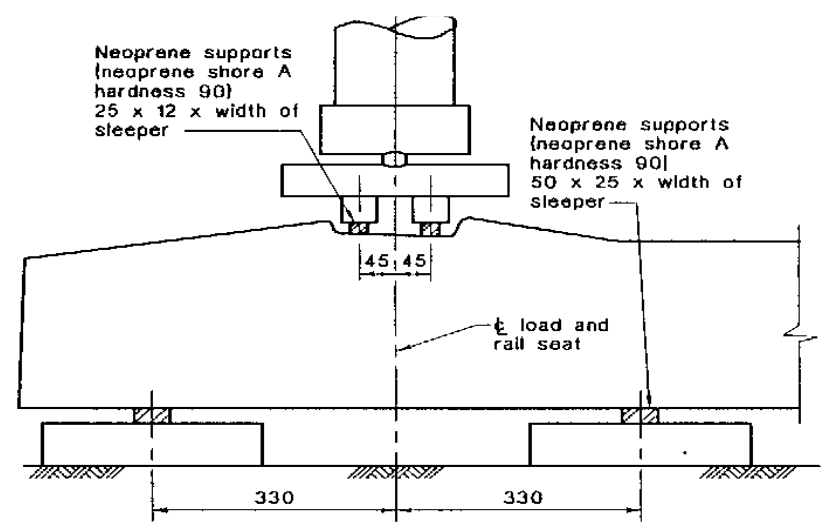

Fig. 4.Support and loading placement in positive moment test. 


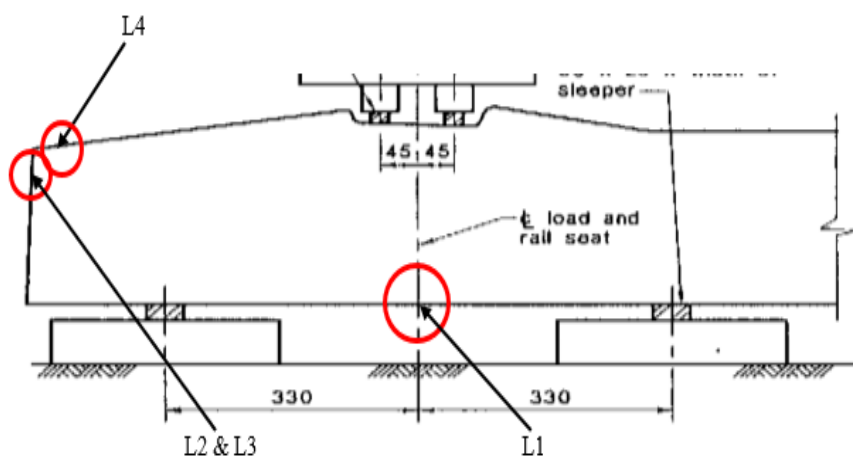

Fig. 5.LVDT placement in positive moment test.

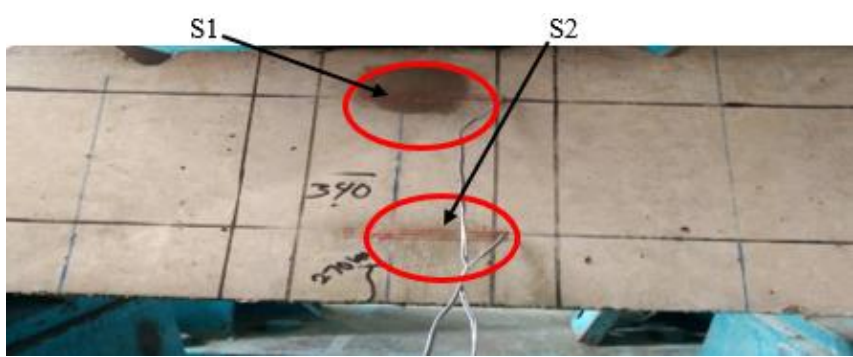

Fig. 6.Strain gauge on the surface of PMCS in positive moment test.

The surface of the PMCS needed to be in smooth condition to attach the strain gauge. So, with the application of the sandpaper, the surface of PMCS was brushed off and the strain gauge were attached with special adhesive material. In positve moment test, two (2) $60 \mathrm{~mm}$ strain gauge were used and attached on the surface of PMCS, parallel to the highest and lowest tendon as shown in figure 6 , given by the name $\mathrm{S} 1$ at the top and $\mathrm{S} 2$ at the bottom.

In this experiment, PMCS was setup into the reaction frame according to Australian Standard like in figure 4, 5 and 6. Computer and data logger were prepared earlier and connected together with L1, L2, L3, L4, S1 and S2 to record its reading. By the Standard, the load rate must be $25 \mathrm{kN} / \mathrm{min}$ or $0.42 \mathrm{kN} / \mathrm{sec}$ to reach PMCS's design load, $176.94 \mathrm{kN}$ to create proof rail seat negative moment. In 3 minutes, the design load was maintained and during that time, any cracks occur was recorded by using any recording instrumental such as camera and video camera. Then, the load will continue to be subjected to the PMCS until reaching its ultimate load. Finally, the data will be transferred and recorded in the computer for further analysis. Following the similar steps, the other end of the PMCS was tested as well.

\section{RESULT AND DISCUSSION}

Negative moment test were tested with a UTM machine and by using 3 samples to achieve their results. From sample 1 , the deflection have a crack with the length of $5.9 \mathrm{~mm}$ for sample 1 and $7.0 \mathrm{~mm}$ for sample 3 . In negative moment test, earlier cracks needed to be taken to see any changes before and after the test. Due to small scale of precrack before the test, high precision microscope were needed to record its location and measure its length for analysis. In negative moment test, both rail seat side of PMCS were named KTM and EP to differentiate their results. In figure 7, new post-crack were produced on EP sides with the length of $9.0 \mathrm{~mm}$. However, the post-crack is too large for the microscope to record its whole length and only capable to record only $3.267 \mathrm{~mm}$. Meanwhile, table 1 shows the changes of the length of crack before and after the negative moment test.

Table-I: Length of crack for PMCS's rail seat in negative moment test

\begin{tabular}{|c|c|c|}
\hline Rail Seat & Precrack $(\mathrm{mm})$ & Post-crack $(\mathrm{mm})$ \\
\hline KTM & 2.481 & 2.481 \\
\hline \multirow{2}{*}{ EP } & 2.605 & 2.605 \\
\cline { 2 - 3 } & 0.000 & 9.000 \\
\hline
\end{tabular}

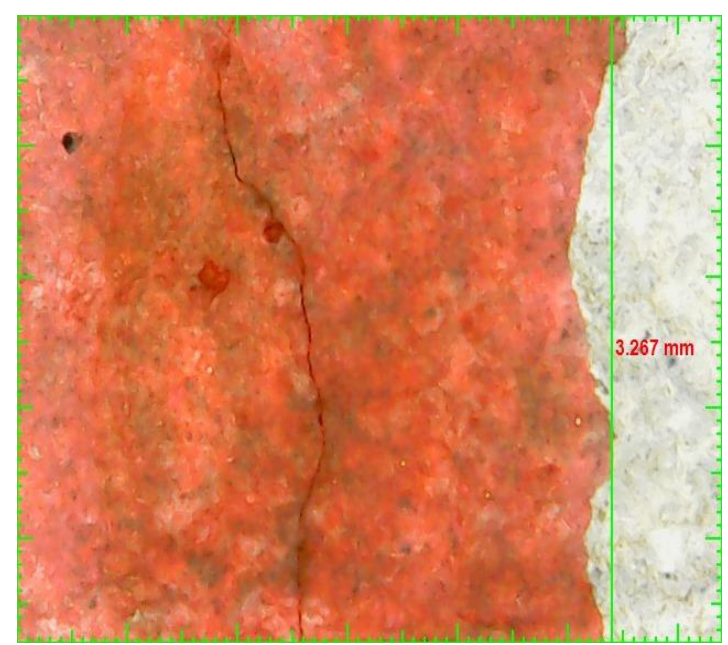

Fig. 7.Crack produced on EP sides.

Referring to past researchers [8] [9] [10], positive moment test were tested with a UTM machine to gain their respective results. In this research, 3 samples were used and from sample 1 , the maximum load cater would be $362 \mathrm{kN}$ and $392 \mathrm{kN}$ for sample 3 . Then, the deflection have a crack with the length of $7.9 \mathrm{~mm}$ for sample 1 and $14 \mathrm{~mm}$ for sample 3 . In positive moment test, both rail seat side of PMCS were named KTM and EP to differentiate their results. With the load rate of $25 \mathrm{kN} / \mathrm{min}$ approximately seven (7) minutes to reach design load, the load were maintained for three (3) minutes to see any structural cracking occur on the surface of the PMCS, similar to negative moment test. After three (3) minutes, the load continued to subjected on PMCS until reached its ultimate load capacity. In figure 8 until 15, the graph shows the relationships between load, deflection and strain on EP and KTM rail seat sides when reaching the ultimate load capacity of the PMCS samples. For KTM rail seat side, the post-crack was $7.7 \mathrm{~mm}$ and $6.8 \mathrm{~mm}$ for EP rail seat side. As shown in the graphs, when the load gradually increasing, the deflection of the PMCS and its tendon were also increasing. Similar occurences with the relationships between load and strain, the strain value increasing as the value of the load subjected to the PMCS increasing. Furthermore, the maximum load cater for EP and KTM rail seat would be $400 \mathrm{kN}$ and $405 \mathrm{kN}$ respectively. 


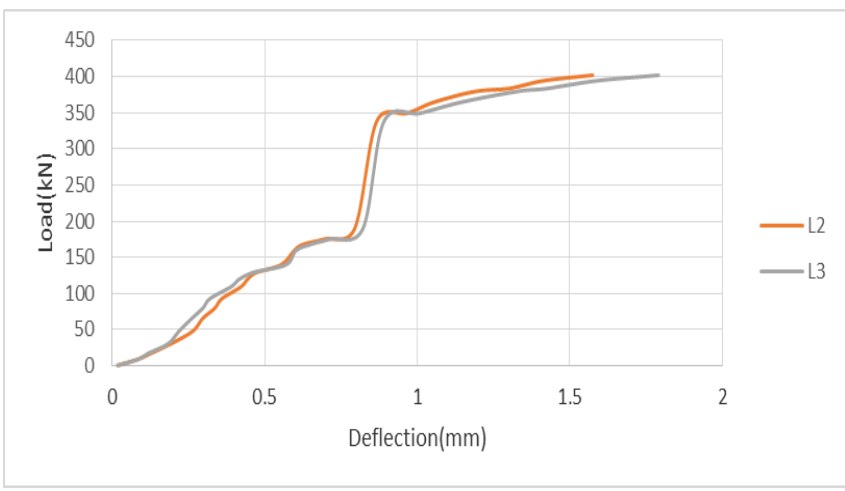

Fig. 8.Relationships between load and deflection at EP rail seat side (L2 \& L3).

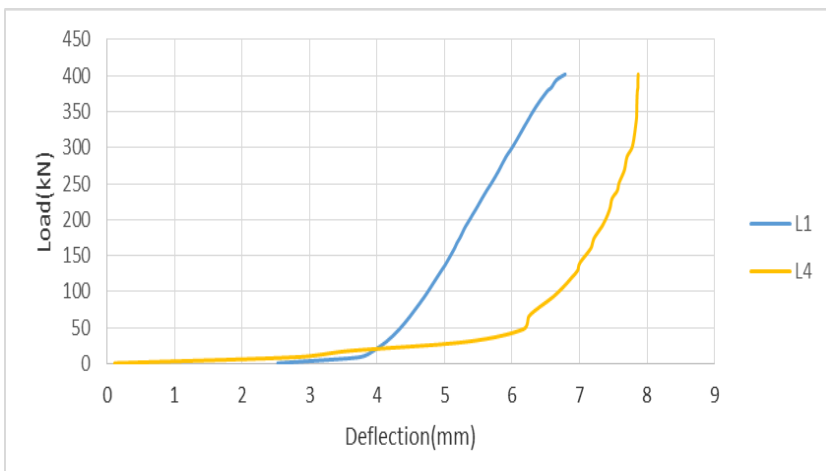

Fig. 9.Relationships between load and deflection at EP rail seat side (L1 \& L4).

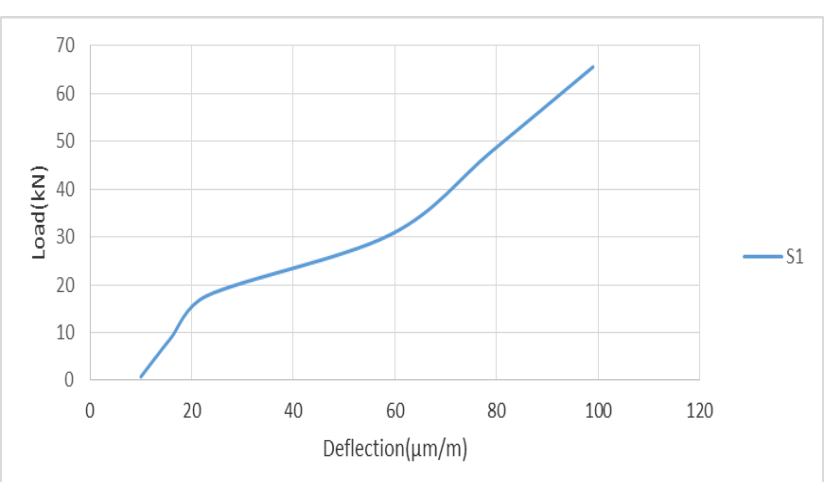

Fig. 10.Relationships between load and strain at EP rail seat side (S1).

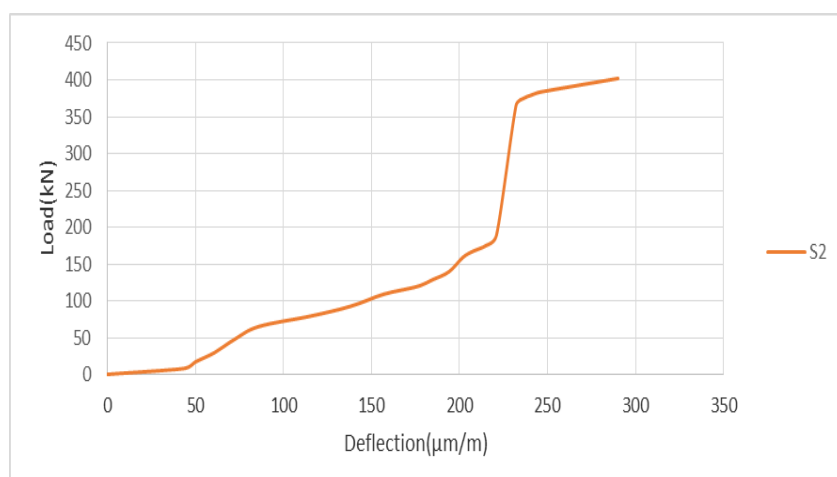

Fig. 11.Relationships between load and strain at EP rail seat side (S2).

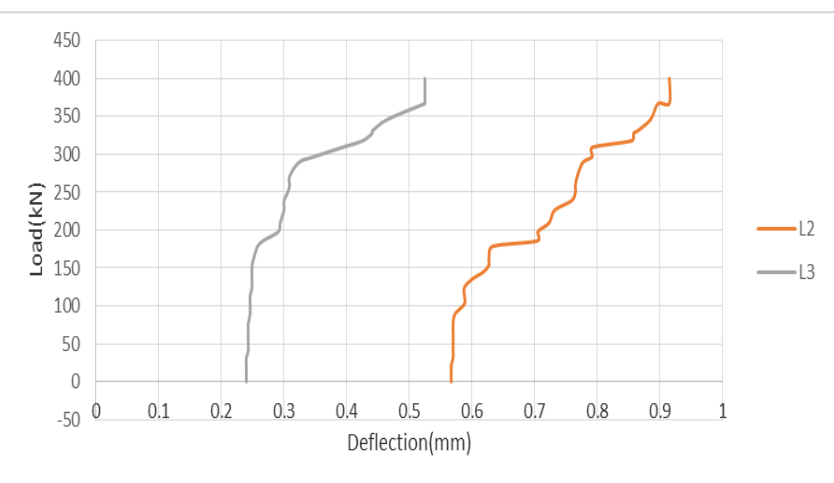

Fig. 12. Relationships between load and deflection at KTM rail seat side (L2 \& L3).

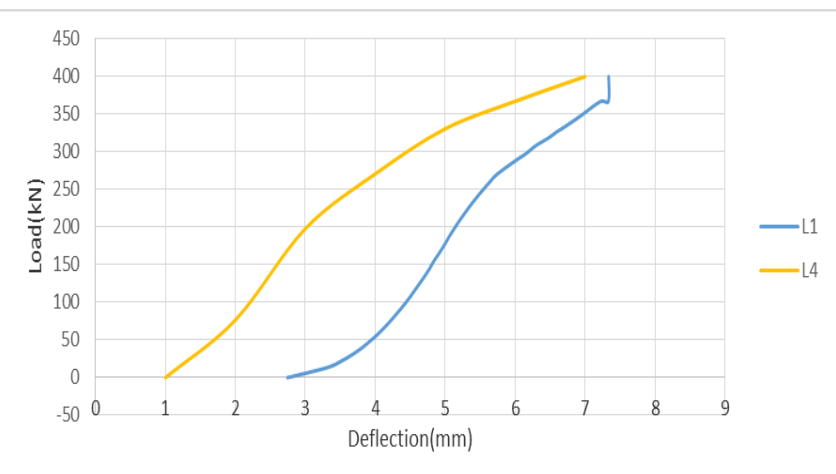

Fig. 13. Relationships between load and deflection at KTM rail seat side (L1 \& L4).

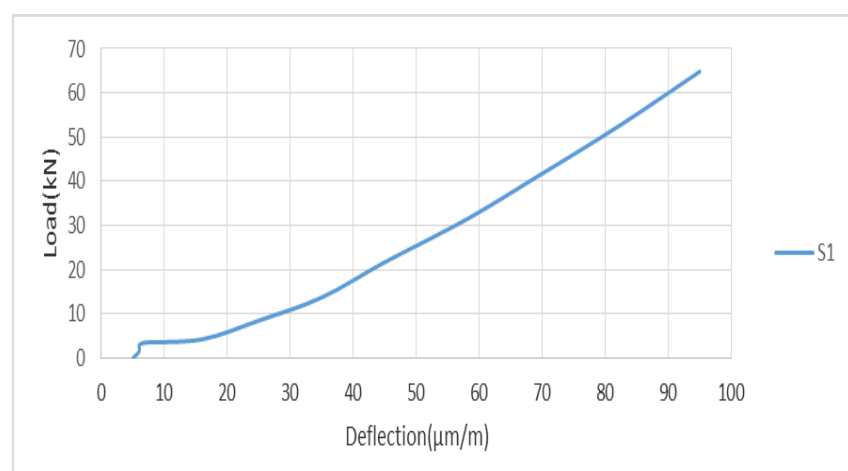

Fig. 14.Relationships between load and strain at KTM rail seat side (S1).

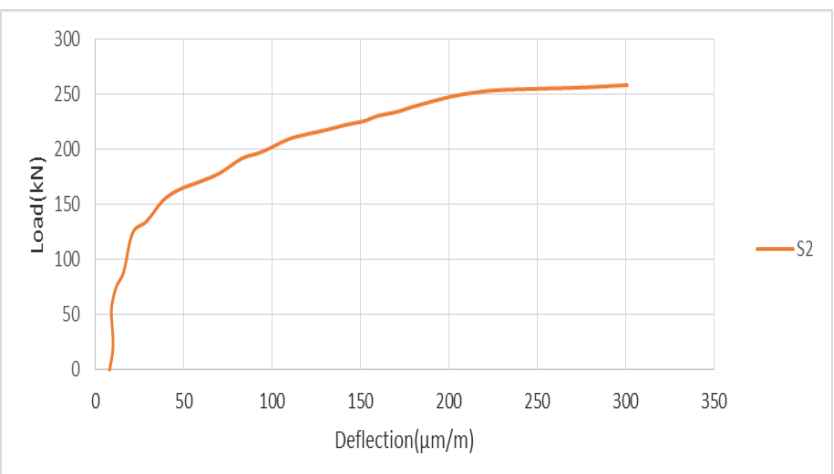

Fig. 15.Relationships between load and strain at KTM rail seat side (S2).

Published By:

Blue Eyes Intelligence Engineering

\& Sciences Publication 


\section{CONCLUSION}

In this research, no cracking were produced from positive moment test when design load of $176.94 \mathrm{kN}$ subjected to PMCS. While in negative moment test, post-crack with a length of $9.0 \mathrm{~mm}$ were produced after the design load were subjected to PMCS. Meanwhile, no changes produced from precrack for KTM and EP rail seat sides. For ultimate load, both PMCS on EP side results in failure when a load of 400 $\mathrm{kN}$ subjected on them. As for KTM side on one concrete sleeper, the ultimate load achieved is $405 \mathrm{kN}$.

\section{ACKNOWLEDGMENT}

The authors would like to express their sincere gratitude to Ministry of Education Malaysia (MOE) as the main sponsor for this overall research under FRGS scheme (600-IRMI/FRGS 5/3 (089/2017)). A special appreciation also goes to Research Management Centre (RMC) and Faculty of Civil Engineering, UiTM Pulau Pinang and Shah Alam for providing facilities and guidance that helped this research to be completed and special thanks to Eastern Pretech SDN BHD for the sample provided to us.

\section{REFERENCES}

1. M. I. F. Rozli, N. I. Sharul, A. B. Afidah and S. H. Hamzah, "Converting Constant Amplitude Loading of Prestressed Concrete Sleeper (PCS) From Variable Amplitude", Jurnal Teknologi (Sciences \& Engineering) 76:11 (2015) 53-56

2. D. K. Kumar and K. Sambasivarao, "Static and Dynamic Analysis of Railway Track Sleeper", International Journal of Engineering Research and General Science Volume 2, Issue 6 , October-November, 2014

3. M. I. F. Rozli, A. A. Bakar, N. M. Amin, K. D. A. Ghani and M. N. Masre, "Structural Behaviour of Prestressed Concrete Sleeper (PCS) Subjected To Static Loading", International Congress on Innovations in Civil Engineering Vol. 3 No. 1 (20XX) p. 1-4

4. S. Kaewunreun and A. Remennikov, "Experimental and Numerical Studies of Railway Prestressed Concrete Sleepers under Static and Impact Loads", Civil Computing, 2007, 3, 25-28

5. M. I. F. Rozli, N. I. Sharul, A. B. Afidah and S. H. Hamzah,”Constan amplitude spectrum of three coaches train and cyclic counting on prestressed concrete sleepers (PCS)", Jurnal Teknologi (Sciences \& Engineering) 76:11 (2015) 1-5

6. S. A. Limited, Australian Standard (AS - 1085.14): Railway track material:Prestressed Concrete Sleepers. SAI Global Limited, 2012.

7. S. Kaewunruen and A. Remennikov,"Resistance of railway concrete sleepers to impact loading", Proceedings of the 7th International Conference on Shock and Impact Loads on Structures, Beijing, China, 17-19 October 2007, 489-496

8. A. B. Afidah, D. Khafilah and M. S. Marwi,"Design and Performance of Pre-Stressed Concrete Railway Sleepers Containing Fibres", Scientific Research Journal Universiti Teknologi MARA (UiTM), Malaysia Vol. 4 No. 1, 13-26, 2007

9. H. D. M. Ardalan and H. B. Masoud,'Displacement Measurement of Bending Tests Using Digital Image Analysis Method", IACSIT International Journal of Engineering and Technology, Vol. 4, No. 5 , October 2012

10. M. Shintaro, W. Tsutomu, S. Masamichi, and G. Keiichi, "Analytical Study on Loading Capacity of Prestressed Concrete Sleeper", Procedia Engineering 199 (2017) 2482-2487

\section{AUTHORS PROFILE}

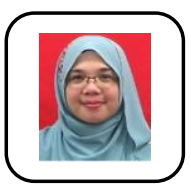

Kay Dora Abd Ghani is a Senior Lecturer in the Faculty of Civil Engineering Universiti Teknologi MARA Cawangan Pulau Pinang and obtained her Ph.D in Civil Engineering (Structural and Material Engineering) from the Faculty of Civil Engineering, Universiti Teknologi MARA (UiTM) in 2015. She is a Graduate Member of Board of Engineers Malaysia. She is now attached as the member of Permanent Way Infrastructure (PWI) Research Interest Group Excellence
Entity Tier 5, Universiti Teknologi MARA Cawangan Pulau Pinang. Her main research interest is in the structural element behaviour under dynamic loading and earthquake engineering field. Her current research focuses on the modeling of existing reinforced concrete buildings under real earthquake data using Ruaumoko 2D, structural performance of precast wall-slab connection in tunnel-form building, and performance of precast/prestressed concrete sleepers when subjected to static and dynamic loadings. She has published more than 40 technical papers in journals and conference proceedings. Due to her expertise and experience, she has been appointed as the panel of evaluator of FRGS for UiTM Cawangan Pulau Pinang; judge in innovation, invention and design competition; reviewer for journals and conference proceedings; and the key person (Conference Co-Chairman for ICACEST2018 and Conference Secretary for ACEE2015) both are international conferences

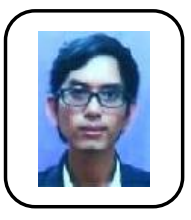

Che Mohd Hilmi Safiuddin Che Jamaludin Mahmud is a fellow researcher in Permeanant Way Infrastrucure Research Group (PWI) in UiTM Pulau Pinang. He is also currently a postgraduate student in Faculty of Civil Engineering UiTM Shah Alam. He is holding a Degree of Science in Civil Engineering (Infrastructure) from Universiti Teknologi MARA.

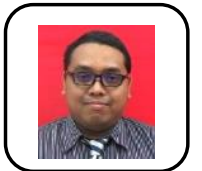

Mohd Ikmal Fazlan Rozli is an academic staff who is currently working in Faculty of Civil Engineering UiTM Pulau Pinang. He is holding a Master of Science in Civil Engineering (Structure) from Universiti Teknologi MARA. He is also currently the Head of Permeanant Way Infrastructure Research Group (PWI) in UiTM Pulau Pinang.

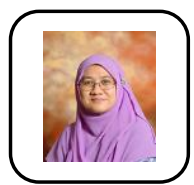

Norliyati Mohd Amin obtained her Bachelor's degree in Civil Engineering from Kyushu Universiti Japan in 1999. In 2007, she received a Master's degree in Structural Engineering from Universiti Teknologi MARA Malaysia. She obtained a PhD in Structural Engineering from Kyushu University in 2011. She has been serving UiTM since January 2001 as a senior lecturer at the Faculty of Civil Engineering. Her research interest includes computational mechanics, Finite Element Method, modal analysis method and seismic engineering. Her PHD thesis is "Development of Fast Dynamic FEM Tool Using Model Order Reduction for Rational Design of Seismic Isolated Bridge" in 2011.

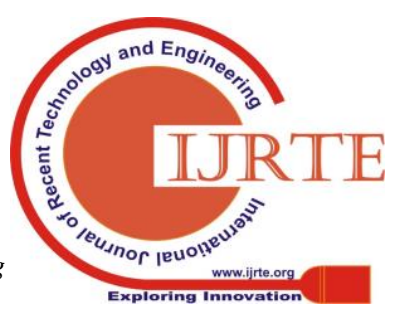

